\title{
DC-DC Buck Converter Parameter Identification Based on a White-Box Approach
}

\author{
Topic number: Power Electronics in Transportation
}

\begin{abstract}
This paper proposes to use a white-box approach to identify the parameters of a DC-DC buck converter. The proposed method is used to calculate the system parameters from the open loop and closed loop outputs, that is, the steady state and transient state stages of the output signals. The approach is validated by comparing simulation results from PSIM models of the converter with experimental data obtained from a commercial non-synchronous buck converter. Both simulation and experimental results show the feasibility and accuracy of the proposed approach in identifying the parameters of the converter, thus being feasible to obtain a full representation of such power converter.
\end{abstract}

\section{INTRODUCTION}

Traditional power converter modelling has been focused on the design of single converters themselves, rather than to model systems integrating multiple power converters. However, nowadays, in sectors such as automotive, avionics or naval, due to the integration of complex power systems comprising multiple electrical machines and/or several electronic devices such as power converters, rectifiers or filters, among others, the trend is to integrate systems comprising multiple converters. Custom approaches to model power converter require an exhaustive analysis of the internal signals and a detailed description of the internal structure of the power converter. However, complex power systems often comprise different power converters from different manufacturers, which usually provide limited information about the internal structure of the power converters. This information often is not enough to generate a detailed model, although excessive detailed models may lead to unacceptable computational resources required [1]. Design inaccuracies arising from load changes or poor load knowledge, unpredicted external disturbances, component tolerances, ageing of components, different ambient conditions or changes in the parameters of the PID controller, among others, may affect the performance of the power converter over time. Consequently, these uncertainties must be considered during the modeling stage of the power converter. System identification methods can partially offset these issues [2].

Therefore, when designing power converters, it is not always feasible for the design engineers to know all the parameters of every component beforehand [3]. However, it is feasible to measure the input and output voltages and currents of the converter. This work deals with these measured data to perform a system identification of the DCDC buck converter.

Parameter identification is an experimental methodology intended to determine the dynamics of a system by applying specifically designed algorithms [4]. However, an accurate parameter identification to allow a precise and realistic prediction of the converter behavior is a challenging problem, due to the complexity of such systems and the variety of operating conditions. Parameter identification methods are specially intended for white-box models, which are based on a detailed mathematical description of the analyzed device or system. However, there are other approaches for parameter identification, including black-box and grey-box models.

Fig. 1 shows the main features of white-, grey- and blackbox models, in which it is seen that white-box models require a detailed knowledge of the physical laws governing the behavior of system to study, in the case, the power converter.

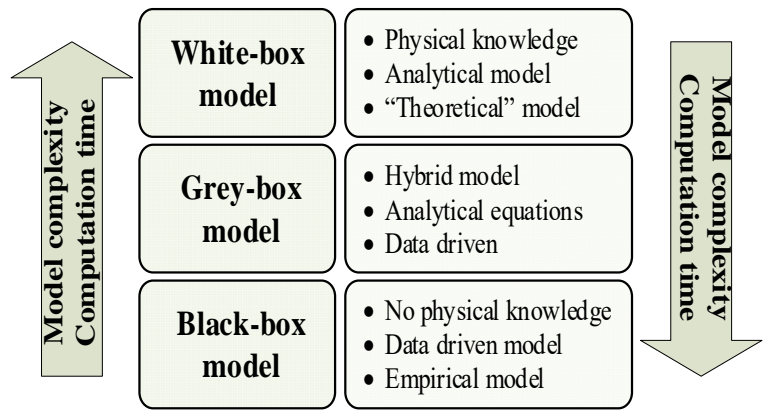

Fig. 1. White-box, grey-box and black-box models

White-box physical modelling apply a specific set of algebraic and/or differential equations to describe the physical behavior of the analyzed system [5], at the expense of the computational effort [6]. Therefore, white-box models assume a known structure for the system, since they are based on theoretical models requiring a deep physical a priori knowledge of the problem.

Parameter identification and estimation under dynamic conditions have been effectively applied to identify circuit and machine parameters based on the measurement of electrical magnitudes such as instantaneous voltages and currents, even from real-time operating data [7]. However, it is known that model parameters can depend on the operating conditions. The identification of such parameters from experimental data can be done both offline or online, either in the frequency- or in the time-domain. In the technical literature, different approaches are found to identify the parameters of power converters. In [8], the closed loop 
parameters are estimated using state space models, which consider the parasitic elements of the converter. In [9], a novel based approach based on continuous time models is developed, and a polynomial interpolation method, together with the least squares algorithm are applied to estimate the parameters of the converter, such as the inductor, capacitor and the parasitic elements, but not the closed loop parameters.

In this work a white-box parameter identification approach is carried out in a DC-DC buck converter, based on both, simulated and experimental data. The approach proposed in this paper is able to estimate the parameters of the buck converter from both, the steady state (open loop) and transient state (closed loop) responses. These parameters include the inductor, capacitor, parasitic elements and the closed loop parameters (zeros and poles of the controller transfer function). By this way, once the parameters are identified, the response of the power converter can be reproduced under different operating conditions, thus providing a fullrepresentation of the converter.

\section{THE PROPOSED APPROACH}

In this section the strategy proposed to identify the parameters of the buck converter is presented. To this end, two approaches are applied. In the first one the parameters of the open loop model are estimated, based on steady state data. The second approach is based on transient data, from which the closed loop parameters are obtained.

\section{A. Open loop parameter estimation}

The open loop model is used to estimate the values of the inductor $(L)$, capacitor $(C)$, inductive resistance $\left(R_{L}\right)$ and the capacitive resistance $\left(R_{C}\right)$. The open loop model during $T_{o n}$ is shown in Fig. 2.

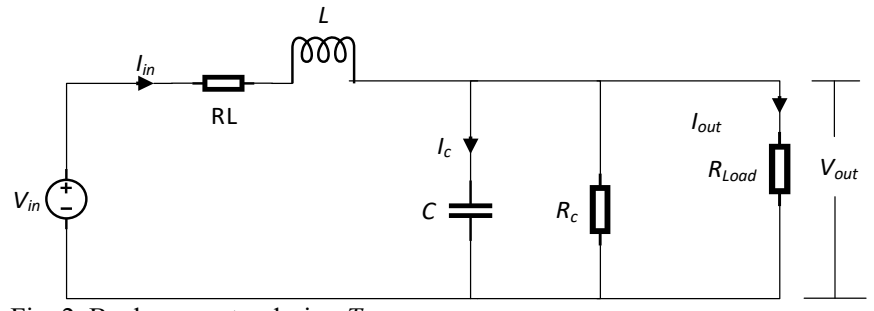

Fig. 2. Buck converter during $T_{\text {on }}$

The equations governing the dynamics of the buck converter are as follows,

$$
I_{\text {in }}=C \cdot \frac{d V_{\text {out }}}{d t}+\frac{V_{\text {out }}}{R_{C}}+I_{\text {out }}
$$

By integrating (1) it results in,

$$
\int d V_{\text {out }}=\frac{1}{C} \int\left(I_{\text {in }}-I_{\text {out }}-\frac{V_{\text {out }}}{R_{C}}\right) d t
$$

The trapezoidal rule allows approximating the integrals in (2) into a difference equation, so (2) results in,

$$
\begin{aligned}
V_{\text {out }, T_{2}}-V_{\text {out }, T_{1}}= & \frac{T_{2}-T_{1}}{2 C}\left[\left(I_{\text {in }, T_{2}}-I_{\text {out }, T_{2}}+I_{\text {in }, T_{1}}-I_{\text {out }, T_{1}}\right)\right. \\
& \left.-\frac{1}{R_{c}}\left(V_{\text {out }, T_{2}}+V_{\text {out }, T_{1}}\right)\right]
\end{aligned}
$$

By considering four instants of time $T_{1}, T_{2}, T_{3}, T_{4}$ in (3), the equations to determine $C$ and $R_{C}$ are as follows,

$$
\begin{aligned}
& {\left[\begin{array}{l}
V_{\text {out }, T_{2}}-V_{\text {out }, T_{1}} \\
V_{\text {out }, T_{4}}-V_{\text {out }, T_{3}}
\end{array}\right]=} \\
& {\left[\begin{array}{ll}
\frac{\left(I_{\text {in }, T_{2}}-I_{\text {out }, T_{2}}+I_{\text {in, }, T_{1}}-I_{\text {out }, T_{1}}\right) \cdot\left(T_{2}-T_{1}\right)}{2} & \frac{\left(-V_{\text {out }, T_{2}}-V_{\text {out }, T_{1}}\right) \cdot\left(T_{2}-T_{1}\right)}{2} \\
\frac{\left(I_{\text {in }, T_{4}}-I_{\text {out }, T_{4}}+I_{\text {in }, T_{3}}-I_{\text {out }, T_{3}}\right) \cdot\left(T_{4}-T_{3}\right)}{2} & \frac{\left(-V_{\text {out }, T_{4}}-V_{\text {out }, T_{3}}\right) \cdot\left(T_{4}-T_{3}\right)}{2}
\end{array}\right] \cdot\left[\begin{array}{c}
\frac{1}{C} \\
\frac{1}{R_{c} \cdot C}
\end{array}\right]}
\end{aligned}
$$

Similarly, the values of $L$ and $R_{L}$ are determined as follows,

$$
V_{\text {in }}-V_{\text {out }}=I_{\text {in }} \cdot R_{L}+L \cdot \frac{d I_{\text {in }}}{d t}
$$

By integrating (5) it results in

$$
\int d I_{\text {input }}=\int \frac{V_{\text {input }} \cdot d t}{L}-\int \frac{V_{\text {output }} \cdot d t}{L}-\frac{R_{L}}{L} \int I_{\text {input }} \cdot d t
$$

By applying the trapezoidal rule (6) is converted into (7),

$$
\begin{aligned}
I_{i n, T_{2}}-I_{i n, T_{1}} & =\frac{\left(T_{2}-T_{1}\right)}{2 L}\left[V_{\text {in }, T_{2}}-V_{\text {out }, T_{2}}+V_{\text {in }, T_{1}}-V_{\text {out }, T_{1}}\right) \\
& \left.-\left(I_{i n, T_{2}}+I_{\text {in }, T_{1}}\right) \cdot R_{L}\right]
\end{aligned}
$$

Next, by considering four instants of time $T_{1}, T_{2}, T_{3}, T_{4}$ in (7), the values of $L$ and $R_{L}$ are calculated as,

$$
\begin{aligned}
& {\left[\begin{array}{l}
I_{i n, T_{2}}-I_{i n, T_{1}} \\
I_{i n, T_{4}}-I_{i n, T_{3}}
\end{array}\right]=} \\
& {\left[\begin{array}{cc}
\frac{\left(V_{i n, T_{2}}-V_{\text {out }, T_{2}}+V_{\text {in, }, T_{1}}-V_{\text {out }, T_{1}}\right) \cdot\left(T_{2}-T_{1}\right)}{2} & \frac{\left(-I_{i n, T_{2}}-I_{\text {in }, T_{1}}\right) \cdot\left(T_{2}-T_{1}\right)}{2} \\
\frac{\left(V_{\text {in }, T_{4}}-V_{\text {out }, T_{4}}+V_{\text {in }, T_{3}}-V_{\text {out }, T_{3}}\right) \cdot\left(T_{4}-T_{3}\right)}{2} & \frac{\left(-I_{i n, T_{4}}-I_{i n, T_{3}}\right) \cdot\left(T_{4}-T_{3}\right)}{2}
\end{array}\right] \cdot\left[\begin{array}{c}
\frac{1}{L} \\
\frac{R_{L}}{L}
\end{array}\right]}
\end{aligned}
$$

It is noted that from (4) and (8) the $C, R_{C}, L$ and $R_{L}$ parameters are calculated at every time step $T_{i}$.

\section{B. Closed loop parameter estimation}

DC/DC converters usually include a closed control loop, as shown in Fig. 3, based on an analog or digital controller to regulate and stabilize the output voltage $V_{\text {out }}$ according to the reference value, $V_{\text {ref }}$.

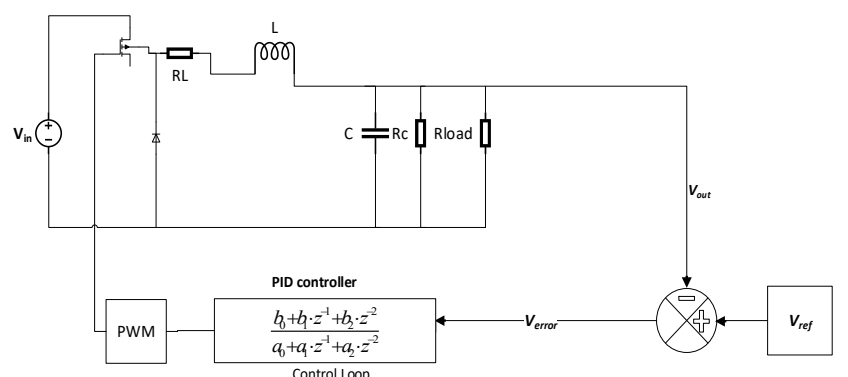

Fig. 3. Closed loop buck converter

The parameters of the control loop are estimated during the transient state. The transients can be generated either by adding a random noise to the input voltage, by adding a 
switching on and off resistance in parallel with the load of the converter and by understanding the startup dynamics of the converter. In this work, the transient data is obtained by using the dynamics of the startup of the converter, in order to allow the identification of the parameters.

A transfer function given by the ratio $D / V_{\text {error }}$ is evaluated, $D=T_{o n} /\left(T_{o n}+T_{o f f}\right)$ being the duty cycle, and $V_{\text {error }}$ the error signal, as shown in Fig. 4. The general representation of the continuous transfer function of the closed loop is given by,

$$
H(z)=\frac{D(z)}{V_{\text {error }}(z)}=\frac{b_{0}+b_{1} \cdot s^{1}+b_{2} \cdot s^{2}+\ldots b_{n a} \cdot s^{n a}}{a_{0}+a_{1} \cdot s^{1}+a_{2} \cdot s^{2}+\ldots . a_{n b} \cdot s^{n b}}
$$

$n_{a}$ being the number of zeros and $n_{b}$ the number of poles of the system. The control loop coefficients are estimated based on the number of poles and zeros of the system. The TPS40200EVM-002 non-synchronous buck converter used in this paper has one zero and two poles in the control loop. The schematic of the control loop is represented in Fig. 4.

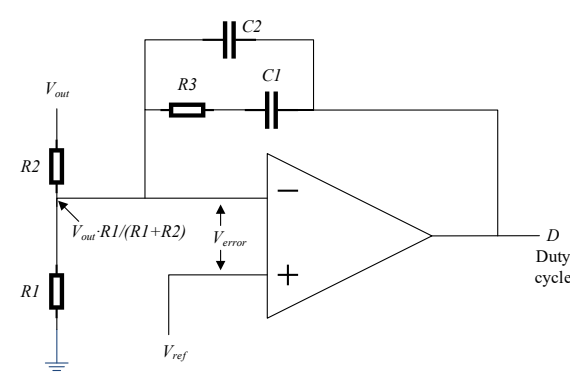

Fig. 4. Control loop of the TPS40200EVM-002 non-synchronous DC-DC buck converter.

The closed control loop transfer function is expressed as [10],

$$
H(s)=-\frac{\left(1+s \cdot R_{3} C_{1}\right)}{s \cdot R_{2} \cdot\left(C_{1}+C_{2}\right) \cdot\left(1+s \cdot \frac{C_{1} \cdot C_{2} \cdot R_{3}}{C_{1}+C_{2}}\right)}
$$

Hence, a one-zero and two-pole system is considered for the analysis, so the closed control loop transfer function is given as,

$$
H(z)=\frac{D(z)}{V_{\text {error }}(z)}=\frac{b_{0}+b_{1} \cdot s}{a_{0}+a_{1} \cdot s+a_{2} \cdot s^{2}}
$$

It is noted that coefficients $a_{0}, a_{1}, a_{2}, b_{0}$ and $b_{1}$ will be identified by means of the tfest function of Matlab [11].

\section{SimULATION DATA}

In this section a parameter identification of the DC-DC buck converter is performed from simulated data obtained from models performed with the commercial software PSIM.

Fig. 5 shows the PSIM model of the TPS40200EVM-002 DC-DC buck converter, which is used in this work to check the suitability of the proposed approach.

From the PSIM simulation, the input voltage, input current, output voltage and output current are obtained. These values are used for calculating the open loop and closed loop parameters, whose simulated (actual) and identified values are shown in Tables I and II, respectively.

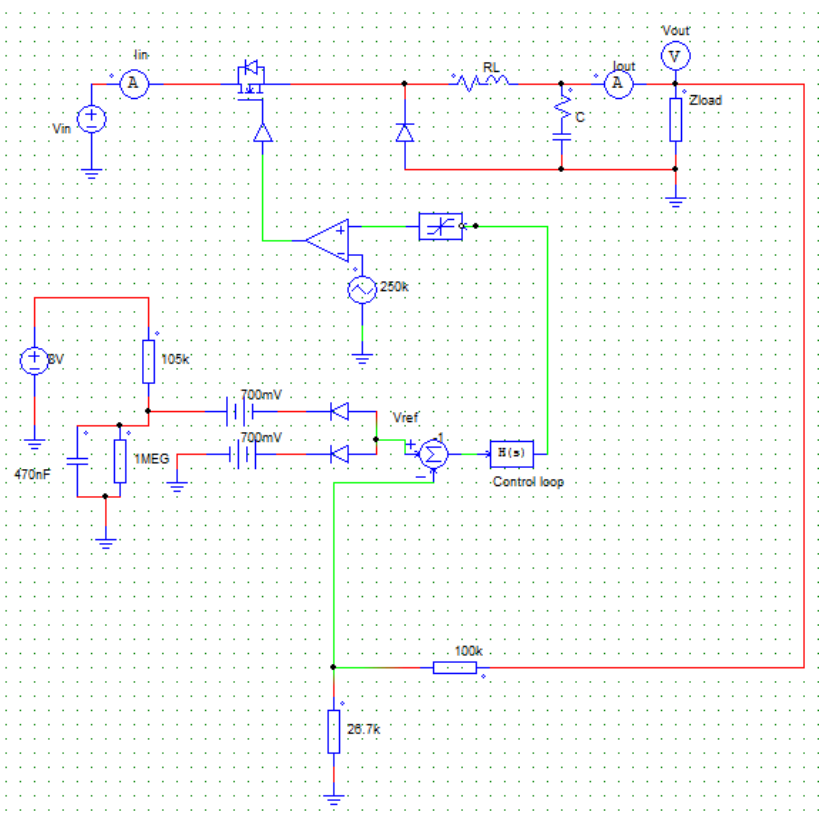

Fig. 5. PSIM model of TPS40200 DC-DC buck converter.

TABLE I

COMPARISON OF ACTUAL AND ESTIMATED OPEN LOOP PARAMETERS

\begin{tabular}{|c|c|c|}
\hline Parameters & Actual (simulated) & Estimated \\
\hline$L$ & $33 \mu \mathrm{H}$ & $33 \mu \mathrm{H}$ \\
\hline$C$ & $460 \mu \mathrm{F}$ & $460 \mu \mathrm{F}$ \\
\hline$R_{L}$ & $60 \mathrm{~m} \Omega$ & $60 \mathrm{~m} \Omega$ \\
\hline$R_{c}$ & $855 \mathrm{~m} \Omega$ & $855 \mathrm{~m} \Omega$ \\
\hline
\end{tabular}

TABLE II

COMPARISON OF ACTUAL AND Estimated Closed LoOp COEFFICIENTS

\begin{tabular}{|c|c|c|}
\hline Parameters & Actual (simulated) & Estimated \\
\hline$a_{0}$ & 0 & $3.326 \cdot 10^{-2}$ \\
\hline$a_{1}$ & $4.733 \cdot 10^{-4}$ & $8.538 \cdot 10^{-4}$ \\
\hline$a_{2}$ & $1.551 \cdot 10^{-9}$ & $1.0 \cdot 10^{-9}$ \\
\hline$b_{o}$ & 1.0 & 1.67 \\
\hline$b_{1}$ & $4.7 \cdot 10^{-4}$ & $6.191 \cdot 10^{-4}$ \\
\hline
\end{tabular}

Fig. 6 compares simulation results performed with the actual parameter values, against simulation results obtained by considering the estimated parameters. It shows a good agreement between both results, thus validating the proposed method.

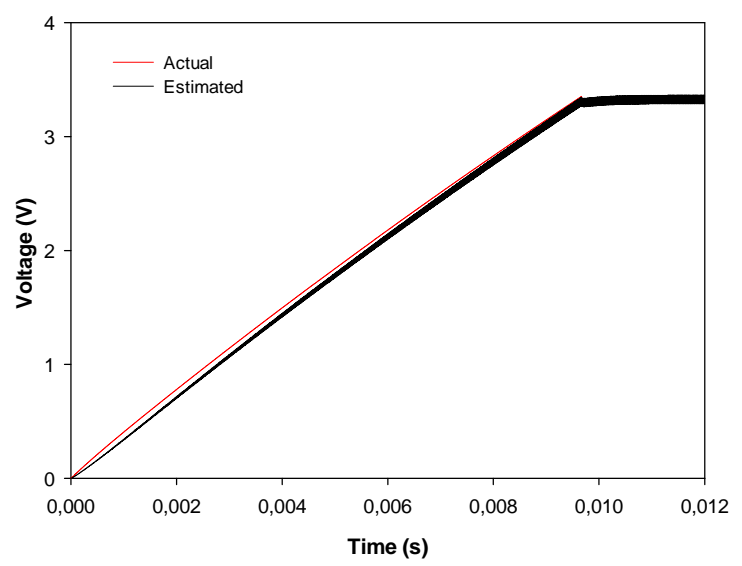

Fig. 6. Simulation results. Output voltage comparison based on actual and identified converter (open and closed loop) coefficients. 


\section{EXPERIMENTAL RESULTS}

\section{Experimental setup}

The TPS40200EVM-002 non-synchronous buck converter from Texas Instruments was used to obtain the experimental data, which is shown in Fig. 7. It is designed to operate with an input voltage in the range $18-36 \mathrm{~V}$. The output voltage was regulated at $3.3 \mathrm{~V}$, whereas the load current was regulated between 0.125 and $2.5 \mathrm{~A}$.

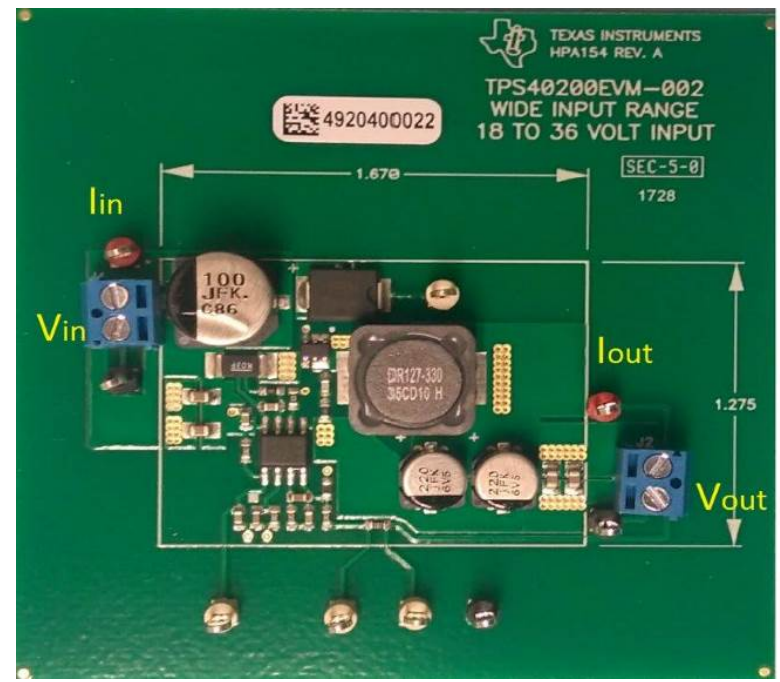

Fig. 7. The input voltage, input current, output voltage and output current terminals of the TPS40200EVM-002 non-synchronous buck converter.

A BK Precision 9205 power supply was used to provide the input signal of the converter, which was connected to a 2 ohms load.

The output and input voltages and currents were acquired by means of a $200 \mathrm{MHz}$ four channel RTH1004P04 digital oscilloscope from Rohde \& Schwarz.

The input and output currents were measured using two HAMEG HZ-56 current probes, which have a current range between $1 \mathrm{~mA}$ and $20 \mathrm{~A}$.

Fig. 8 shows the experimental setup of the TPS40200EVM-002 non-synchronous buck converter.

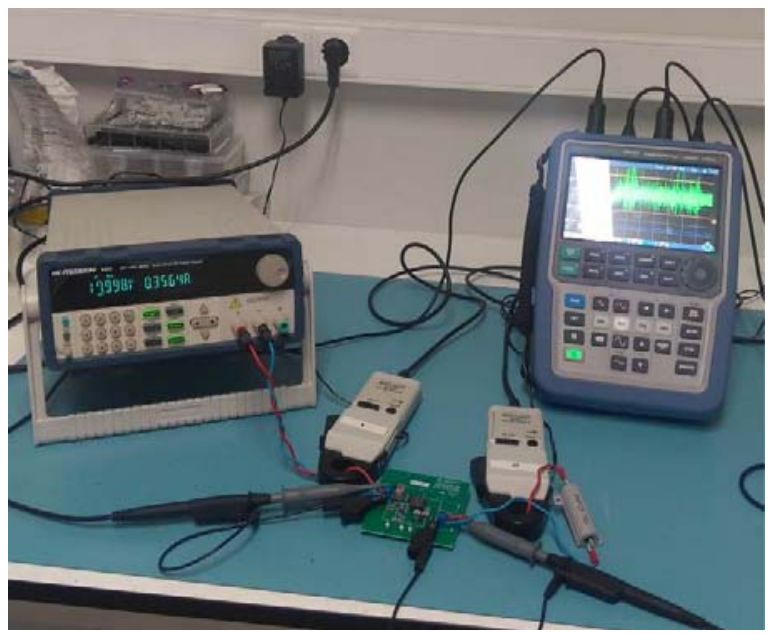

Fig. 8. Experimental setup including the TPS40200EVM-002 nonsynchronous buck converter, the electronic board, the load, the oscilloscope, power source and the current probes.

\section{Results}

Results presented in this section are based on experimental data taken from the setup detailed in Fig. 6.

\section{Open loop results (steady-state operation)}

The experimental data is obtained from the TPS40200EVM-002 non-synchronous buck converter.

The $I_{\text {in }}, V_{\text {in }}, I_{\text {out }}$, and $V_{\text {out }}$ signals were measured with the 4 channel oscilloscope, and the parameters of the converter were found using the approach proposed above, whose values are summarized in Table III.

\section{TABLE III}

COMPARISON OF ACTUAL AND ESTIMATED OPEN LOOP PARAMETERS

\begin{tabular}{|c|c|c|}
\hline Parameters & Actual & Estimated \\
\hline$L$ & $33 \mu \mathrm{H}$ & $32.1 \mu \mathrm{H}$ \\
\hline$C$ & $460 \mu \mathrm{F}$ & $458 \mu \mathrm{F}$ \\
\hline$R_{L}$ & $60 \mathrm{~m} \Omega$ & $62 \mathrm{~m} \Omega$ \\
\hline$R_{C}$ & $855 \mathrm{~m} \Omega$ & $843 \mathrm{~m} \Omega$ \\
\hline
\end{tabular}

2. Closed loop parameters (transient-state operation)

To determine the parameters of the closed control, the duty cycle $D$ is required. It was estimated from the experimental data, using the PWM signal, and by applying $D=$ $T_{\text {on }} /\left(T_{\text {on }}+T_{\text {off }}\right)$. From $V_{\text {ref }}$ and $V_{\text {out }}$ the voltage error $V_{\text {error }}$ is determined, and the parameters of the closed loop are identified by means of the $t$ fest function of Matlab from (12).

Table IV compares the actual and estimated closed loop parameters obtained by means of the proposed approach.

TABLE IV

COMPARISON OF ACTUAL AND ESTIMATED ClOSED LOOP COEFFICIENTS

\begin{tabular}{|c|c|c|}
\hline Parameters & Actual & Estimated \\
\hline$a_{0}$ & 0 & 0.0769 \\
\hline$a_{1}$ & $4.733 \cdot 10^{-4}$ & $4.56 \cdot 10^{-4}$ \\
\hline$a_{2}$ & $1.551 \cdot 10^{-9}$ & $1.86 \cdot 10^{-9}$ \\
\hline$b_{o}$ & 1.0 & 1.0 \\
\hline$b_{1}$ & $4.7 \cdot 10^{-4}$ & $3.38 \cdot 10^{-4}$ \\
\hline
\end{tabular}

Finally, Fig. 9 compares the experimental output with that obtained from the PSIM model using the estimated parameters. As shown, there is a good agreement between both, thus validating the approach proposed in this paper.

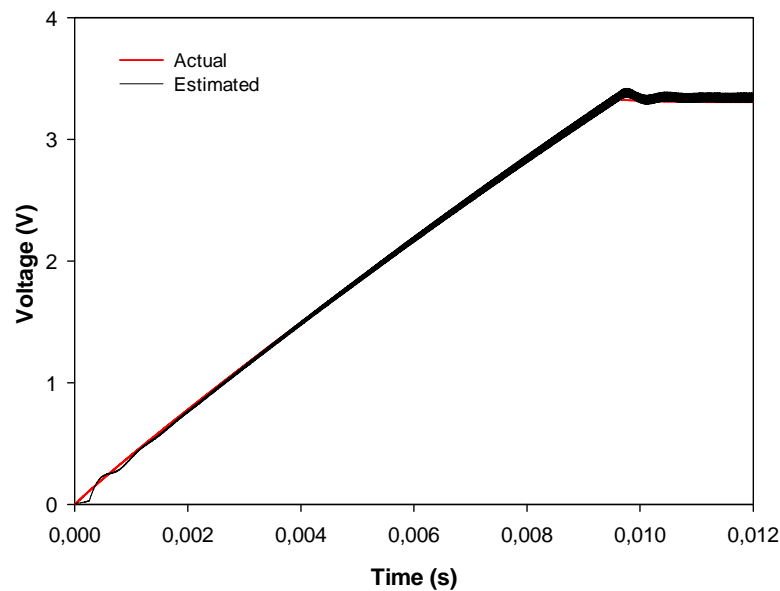

Fig. 9. Experimental results. Output voltage comparison based on actual and identified converter (open and closed loop) coefficients. 


\section{CONCLUSIONS}

This paper has presented a parametric identification approach of a white-box model of a DC-DC buck converter. The parameters of the open loop model are estimated, considering the steady state data and the closed loop parameters are obtained by using the transient state data of the converter. The same approach can be extended to other converters, including boost and buck-boost converters. The approach has been verified using experimental data obtained from a TPS40200EVM-002 non-synchronous DC-DC buck converter. Whereas the open loop parameters have been estimated by solving the differential equations arising from the white-box model of the converter, the closed loop parameters have been estimated from the transfer function of the closed loop control circuit. The parametric identification approach proposed in this work will be further extended to black-box and grey-box models of different architectures of DC-DC converters.

\section{ACKNOWLEDGMENT}

This work has been partially supported by the Generalitat de Catalunya under the project SGR 2017 SGR 967, the Spanish Ministry of Economy and Competitiveness under the project TRA2016-80472-R and the European Commission through the Clean Sky program under the project 755332 AEMS-IdFit.

\section{FUNDING}

This project has received funding from the Clean Sky 2 Joint Undertaking under the European Union's Horizon 2020 research and innovation program under grant agreement No 755332 .
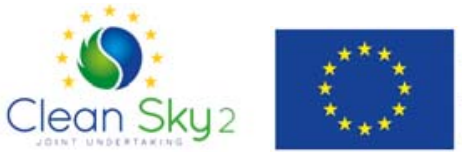

This project was funded by the European Union

\section{DISCLAIMER}

(C) European Union, 2020

The information and views set out in this publication are those of the authors and do not necessarily reflect the official opinion of the European Union. Neither the European Union institutions and bodies nor any person acting on their behalf may be held responsible for the use which may be made of the information contained therein.

Reproduction is authorized provided the source is acknowledged.

\section{REFERENCES}

[1] V. Valdivia, "Behavioral Modeling and Identification of Power Electronics Converters and Subsystems Based on Transient Response,' Carlos III (Madrid), 2013.

[2] M. M. Fawzi Saber Algreer, "Microprocessor Based Signal Processing Techniques for System Identification and Adaptive Control of DC-DC
Converters," Newcastle University, 2012.

[3] J. A. Oliver, R. Prieto, V. Romero, and J. A. Cobos, "Behavioural Modelling of DC-DC Converters for Large-Signal Simulation of Distributed Power Systems," Twenty-First Annu. IEEE Appl. Power Electron. Conf. Expo. 2006. APEC '06., no. 1, pp. 1204-1209, 2006.

[4] D. Munster, "Parameter Identification: A Comparison of Methods," pp. 4-7, 2009.

[5] O. Nelles, Nonlinear System Identification. From Classical Approaches to Neural Networks and Fuzzy Models. Springer-Verlag Berlin Heidelberg, 2001.

[6] Petrone, R., Zheng, Z., Hissel, D., Péra, M. C., Pianese, C., Sorrentino, M., ... Yousfi-Steiner, "A review on model-based diagnosis methodologies for PEMFCs," Int. J. Hydrogen Energy, vol. 38, no. 17, p. 7077-7091., 2013.

[7] Y. Wehbe, L. Fan, and Z. Miao, "Least squares based estimation of synchronous generator states and parameters with phasor measurement units," 2012 North Am. Power Symp. NAPS 2012, 2012.

[8] H. Gietler, C. Unterrieder, A. Berger, R. Priewasser, and M. Lunglmayr, "Low-complexity, high frequency parametric system identification method for switched-mode power converters," Conf. Proc. - IEEE Appl. Power Electron. Conf. Expo. - APEC, pp. 2004-2009, 2017.

[9] G. M. Buiatti, A. M. R. Amaral, and A. J. M. Cardoso, "An unified method for estimating the parameters of non-isolated DC/DC converters using continuous time models," Telecommun. Energy Conf. 2007. INTELEC 2007. 29th Int., pp. 334-341, 2007.

[10]B. A. Francis, B. M. Jos, and B. Thomas, "Single Phase Power Factor Correction Based on Averaged Current Mode Controlled Boost Converter," Int. J. Adv. Res. Electr. Electron. Instrum. Eng., vol. 3, no. 5, pp. 610-622, 2014

[11]M. Ahmeid, M. Armstrong, S. Gadoue, M. Algreer, and P. Missailidis, "Real- Time Parameter Estimation of DC-DC Converters using a Selftuned Kalman Filter," IEEE Trans. Power Electron., vol. 8993, no. DCD, pp. 1-1, 2016. 